\title{
Autopsy examination in sudden cardiac death: a current perspective on behalf of the Association for European Cardiovascular Pathology
}

\author{
Jytte Banner ${ }^{1} \cdot$ Cristina Basso $^{2} \cdot$ Zoe Tolkien $^{3} \cdot$ Ivana Kholova $^{4} \cdot$ Katarzyna Michaud $^{5} \cdot$ Patrick J Gallagher $^{6}{ }_{\mathbb{C}}$
}

Received: 15 June 2020 /Revised: 22 September 2020 / Accepted: 11 October 2020 / Published online: 28 October 2020

(C) The Author(s) 2020

\begin{abstract}
In sudden cardiac death, an autopsy is an essential step in establishing a diagnosis of inherited cardiac disease and identifying families that require cardiac screening. To evaluate aspects of post-mortem practice in Europe, a questionnaire was designed and circulated to both clinical and forensic pathologists. There was a $48 \%$ response rate and information was obtained from 17 countries. The results showed a wide variety in the management of sudden cardiac death, with a general tendency towards a lack of thorough investigation. In up to $40 \%$ of cases, autopsies were not performed in subjects less than 50 years who may have died from cardiac disease. Reasons for this were lack of finance and lack of interest from police, legal authorities, and doctors. Only 50\% of pathologists seem to follow a standard protocol for autopsy examination, apparently due to lack of expertise and/or training. When autopsies were performed, histology and toxicology were almost always taken, genetic studies were generally available and retention of the heart for specialist study was usually permitted. Our results suggest that although the standard of practice is appropriate in many centres, many more cases should have autopsies, especially in sudden deaths in subjects less than 50 years.
\end{abstract}

Keywords Autopsy $\cdot$ Sudden cardiac death $\cdot$ Inherited cardiac conditions — cardiomyopathy

\section{Introduction}

Sudden unexpected death is a frequent complication of many forms of cardiac disease. Because there is no internationally agreed definition of sudden cardiac death, the exact incidence is uncertain [1]. Nevertheless, a task force of the European Society of Cardiology has suggested that the incidence ranges from 36 to 128 deaths per 100,000 population per year [2]. Other

This article is part of the Topical Collection on Quality in Pathology

Patrick J Gallagher

mdzpxg@bristol.ac.uk

1 Department of Forensic Medicine, University of Copenhagen, Copenhagen, Denmark

2 Cardiovascular Pathology Unit, Department of Cardiac, Thoracic and Vascular Sciences and Public Health, University of Padua, Padua, Italy

3 NutriDART, Bristol, UK

4 Fimlab Laboratories, Tampere University Hospital, Tampere, Finland

5 Centre Universitaire Romand de Médecine Légale, Lausanne, Genève, Switzerland

6 Medical Education, Bristol Medical School, Bristol, UK reviews indicate that the incidence is between 50 and 100 per 100,000 population in a range of different countries [3, 4].

Ischaemic heart disease and heart failure are the most common causes $[5,6]$, but there are many other cardiac disorders associated with sudden death [7]. Some of these have a defined genetic basis and are thus inheritable [8]. This is especially the case in children and younger adults [9]. Correct autopsy diagnosis is an indispensable step in diagnosing the underlying pathology in sudden cardiac death and is essential for the subsequent screening and investigation of relatives of victims.

Our association (the Association for European Cardiovascular Pathology, AECVP) has previously produced a guideline for the post mortem investigation of patients who die suddenly from cardiac disease [10], and this has been recently updated [11]. The extensive citation and various translations of this document confirms its apparent value for practitioners around the globe. However, such guidelines are of little value if appropriate cases are not selected for post-mortem examination. The clinical, educational and epidemiological value of autopsy examination was addressed by Burton and Underwood in 2007 [12]. They documented a steep decline in non-forensic autopsies in eight different countries, discussed medical and secular reasons for this decline, and emphasized the 
value of autopsy examination in both undergraduate and post-graduate education. They, and others, have emphasized that autopsies continue to demonstrate important clinically unsuspected pathology [13-15], even in the current era of 'high-tech medicine' [16]. A decline in autopsy examinations is of particular concern in patients who may have died suddenly and unexpectedly from potentially inherited cardiac disorders. While these are only a small percentage of all sudden cardiac deaths, the accurate diagnosis in these cases will guide screening of relatives by cardiologists with expertise in inherited cardiac disorders.

In 2010, Michaud and her colleagues published the results of a survey concerning forensic practice in cases of sudden cardiac death (SCD) [17]. This demonstrated wide variation in the ordering of autopsies and the standard of investigation. Many of the problems were financial in origin, largely because activities in forensic medicine are often paid by, and dependant on, judicial authorities.

In this report we describe the results of a questionnaire into autopsy practice, sent to forensic and hospital pathologists in different European countries and regions. Particular emphasis was on the management of sudden cardiac death in the young.

\section{Materials and methods}

An on line questionnaire was widely circulated to members of the AEVCP and to National Chairpersons of Clinical and Forensic Pathology Societies. The full text of this questionnaire is available in the supplementary appendix. For the purposes of this study, a young sudden cardiac death victim was a subject less than 50 years of age. Questions addressed the following broad issues:

- Registration of the cause of death

- Overall autopsy rate

- Numbers of sudden cardiac deaths

- Selection of sudden cardiac death cases for autopsy

- Additional investigations after autopsy

- Professional interactions with specialist cardiologists, geneticists and pathologists

The results were analysed, discussed by a writing committee and used for the formulation of recommendations at general assemblies and dedicated meetings of the AECVP.

\section{Results}

A selection of the most important results is presented in Table 1 . The following comments are made in summary.

\section{Respondents}

Thirty-one completed questionnaires were returned (48\% response rate). Responses were obtained from 17 different countries. The population on which a response was based ranged from 0.5 to 82 million. The majority of respondents $(21 / 31)$ were forensic pathologists. Twenty respondents worked in a university setting.

\section{Numbers of autopsies performed}

The number of autopsies performed varied considerably. In Denmark, Germany, Italy, Norway, Spain and the Netherlands, $\leq 5 \%$ of all deaths were autopsied in a region of Switzerland, in Slovakia, Ireland and the UK between 10 and 20\%, in Finland $23 \%$ and in separate regions of Russia between 30 and $60 \%$.

In most countries or regions, forensic autopsies were performed in much less than 5\% of all deaths. The rate was between 5 and $10 \%$ in Finland, Portugal, Spain, in a region of the Czech Republic. In contrast forensic autopsies were performed in more than $30 \%$ of deaths in three separate regions of Russia. Many autopsies performed by forensic pathologists were considered to be natural deaths.

Clinical autopsies, performed by hospital-based pathologists, were infrequent, usually much less than $5 \%$ of all deaths. Exceptions included Finland (7\%), Ireland (20\%) and specific regions of Switzerland (20\%), Belgium (23\%) and a region of Russia (64\%).

\section{Autopsies in sudden cardiac death}

Only nine respondents were able to provide detailed information on the numbers of sudden cardiac deaths in subjects of all ages. Denmark, Finland and the St. Petersburg region of Russia have broadly similar populations of $\sim 5$ million but reported 3500, 7500 and 12,000 sudden cardiac deaths per year. Results from individual regions in the Czech Republic, Russia, Spain, and the UK, with populations between 0.8 and 1.65 million, gave an autopsy confirmed sudden death rate of $\sim 50$ per 100,000 per year.

In subjects less than 50 years of age half of the respondents indicated that between 10 and $12.5 \%$ of all deaths were sudden cardiac deaths. National responses from Denmark, Finland, Germany, and the Netherlands suggested that sudden cardiac death rates in subjects less than 50 years were 12.7, $16.0,5.1$ and 13.5 per 100,000 population per year. When asked the question: A subject $<50$ years dies suddenly. Cardiac disease is thought to be the cause of death. How often is an autopsy performed? responses were as follows: always, or almost always, $35 \%$; more than $50 \%$ of cases, $27 \%$; less than $50 \%$ of cases, $35 \%$; never, $3 \%$. 
Table 1 Summary of questionnaire
Questions $\quad$ Summary of responses

On which country are your answers based on? (Number of responses per country)

Are the responses based on a whole country, a region of a country or an individual hospital or department

What is the general opinion about the registration of causes of death?

Are autopsy results considered in official statistics of the causes of death?

What is the overall autopsy rate?

What is the clinical autopsy rate?

What percentage of autopsies performed by forensic pathologists are entirely natural deaths?

In forensic practice who is mainly responsible for ordering an autopsy in a young subject where there are no suspicious circumstances?

In clinical practice who is mainly responsible for ordering an autopsy in a young subject where there are no suspicious circumstances?

In forensic practice is family consent required in order to perform an autopsy on a young sudden death subject?

In clinical practice is family consent required in order to perform an autopsy on a young sudden death subject?

In forensic practice who pays for an autopsy in a young sudden death subject?

In clinical practice who pays for an autopsy in a young sudden death subject?

If an autopsy is NOT performed in a young subject where cardiac disease is thought to be the cause of death what is (are) the reason(s). Multiple responses included
Australia (1); Belgium (2); Czech Republic (1); Denmark (2); Finland (1); France (1); Germany (1); Ireland (1); Italy (4); Netherlands (2); Norway (1); Portugal (1); Russia (5); Slovakia (1); Spain (2); Switzerland (2); United Kingdom (3)

A whole country 10 responses

An individual region of a country 15 responses

An individual hospital or department 6 responses Satisfactory, data are always registered $39 \%$

Not entirely satisfactory, but data are always registered $55 \%$

Not entirely satisfactory, data not always registered $3 \%$

Unsatisfactory, data not reliably entered $3 \%$

Yes $74 \%$

No $19 \%$

Unsure $7 \%$

Less than $10 \%$ of all deaths $37 \%$

Between 10 and $20 \%$ of all deaths $26 \%$

More than $20 \%$ of all deaths $37 \%$

$<5 \%$ of all deaths $43 \%$

$5-10 \%$ of all deaths $21 \%$

$\geq 20 \%$ of all deaths $43 \%$

$<50 \%$ of autopsies $23 \%$

$50-60 \%$ of autopsies $32 \%$

$\geq 60 \%$ of autopsies $45 \%$

Judge $57 \%$

Police $37 \%$

Medical examiner 3\%

Doctor attending death $3 \%$

Doctor attending death $48 \%$

Family doctor $11 \%$

Head doctor $7 \%$

Judge $19 \%$

Others $15 \%$

No $83 \%$

Yes, but can be over ruled by police or judge $14 \%$

Yes 3\%

No $43 \%$

Yes, but can be over ruled by police or judge $14 \%$

Yes $43 \%$

Judge or legal authority $44 \%$

Police $22 \%$

Health authority $30 \%$

Relatives $4 \%$

Health authority $80 \%$

Judge or other legal authority $8 \%$

Relatives $4 \%$

Others $8 \%$

No finance for forensic autopsy 9 responses

No finance for clinical autopsy 5 responses

No interest from police or judge 16 responses

No interest from clinical team 8 responses

No interest from clinical pathologist 7 responses

Other reasons 7 responses 
Table 1 (continued)

Questions
In a young sudden cardiac death autopsy do your
pathologists follow AECVP guidelines?
When pathologists do not follow guidelines what is the
reason(s) Multiple responses included

Do clinical and/or forensic pathologists have established collaborations with specialists in cardiovascular pathology?

Are pathologists permitted to retain the full heart for further examination or referral

Do pathologists require family consent to retain the heart?

Do pathologists order toxicology

Do pathologists perform histology on the heart of a young sudden death subject

Do pathologists make a histological examination of the conduction system

Do pathologists make immunohistochemical studies of cardiac tissue

Do pathologists store frozen tissue for future genetic analyses?

Having retained frozen samples are your pathologists, or their clinical colleagues able to perform genetic analyses?

Who is responsible for ensuring that the relatives of a young sudden cardiac death subject are referred to a cardiologist or clinical geneticist?

Do pathologists have contact with the families of young sudden cardiac death subjects?

Do pathologists have contact with the family doctor of young sudden cardiac death subjects?

Do pathologists have established collaborations with cardiologists and/or geneticists with expertise in inhertited cardiac conditions?
Summary of responses

In every, or almost every, case $30 \%$

In more than half of cases $20 \%$

In less than half of cases $27 \%$

Never, or almost never $23 \%$

Pathologist has insufficient knowledge or training 12 responses

Pathologist has insufficient time 7 responses

Insufficient funds 7 responses

No police or legal interest 3 responses

Other reasons 6 responses

Yes, through recognized centres 29\%

Yes, on a personal basis $49 \%$

Yes, but practice varies $19 \%$

No $3 \%$

Yes, 67\%

Yes, sometimes 23\%

Never or hardly ever $10 \%$

Yes, $17 \%$

No, $80 \%$

Sometimes, 3\%

Always, or in more than $50 \%$ of cases $68 \%$

Never, or in less than $50 \%$ of cases $19 \%$

Only when indicated by post mortem findings $13 \%$

In every, or almost every, case $81 \%$

In more than $50 \%$ of cases $13 \%$

Less than $50 \%$ of cases $6 \%$

In all, or more than $50 \%$, of cases $24 \%$

In less than $50 \%$ of cases $41 \%$

Never 35\%

In all, or more than $50 \%$ of cases $10 \%$

Never, or in less than $50 \%$ of cases $37 \%$

Only when appropriate on the basis of histology $53 \%$

In every case $30 \%$

In more than $50 \%$ of cases $27 \%$

In less than $50 \%$ of cases $20 \%$

Never, or almost never 23\%

Yes for a large panel of relevant genes, $68 \%$

Yes, for a limited panel of genes $16 \%$

No, $16 \%$

Pathologists who performed the autopsy $32 \%$

Family doctor of the deceased $42 \%$

Judge or police $6 \%$

Other responses 20\%

In almost every case, $19 \%$

in $>50 \%$ of cases, $13 \%$

In $<50 \%$ of cases, $29 \%$

Never or almost never, 39\%

In $>50 \%$ of cases $17 \%$

In $<50 \%$ of cases $33 \%$

Never, or almost never 50\%

Yes with cardiologists and cardiologists $49 \%$

Yes but with cardiologists only $3 \%$

Yes, but practice variable 19\% 
Table 1 (continued)

\begin{tabular}{ll}
\hline Questions & Summary of responses \\
\hline & $\begin{array}{l}\text { No established collaboration in the majority of } \\
\text { departments 29\% } \\
\text { Often 30\% }\end{array}$ \\
$\begin{array}{c}\text { How often do pathologists receive clinical or molecular } \\
\text { information from cardiologists or geneticists about } \\
\text { relatives of sudden death subjects? }\end{array}$ & $\begin{array}{l}\text { Sometimes 23\% } \\
\text { Hardly ever 30\% }\end{array}$ \\
$\begin{array}{c}\text { Never 17\% } \\
\text { cardiologists or clinical geneticists about the standard } \\
\text { of post mortem reports? }\end{array}$ & Often 13\% \\
& Sometimes 3\% \\
& Hardly ever 37\% \\
& Never 47\% \\
\hline
\end{tabular}

- In all but two questions only single answers could be given and the results are expressed as percentages. For 2 questions multiple answers were permitted and results are expressed numerically

AECVP Association for European Cardiovascular Pathology

\section{Autopsy guidelines and reports}

The guidelines for autopsy practice in sudden cardiac death produced by our Association were always followed by $30 \%$ of respondents and a further $20 \%$ did so in "more than $50 \%$ " of cases. The remainder did so in "less than 50\%" of cases or never followed guidelines. Reasons for not following guidelines included a lack of knowledge or training of pathologists (12 responses) and insufficient time and/or funds (7 responses each).

\section{Histology, toxicology and molecular studies}

Standard histology and toxicology were performed in most, but not every, autopsy. DNA was extracted from post mortem tissues in the majority of cases and could be screened for a wide number $(68 \%)$ or a limited range $(16 \%)$ of genetic abnormalities (see Table for details).

\section{Discussion and recommendations}

\section{Autopsies in adult subjects}

The objective of the present study was to obtain information about the conduct of sudden cardiac death autopsies. Most of the information that we obtained was from countries in the European Union, but we also obtained information from members of our Association practising in other parts of Europe and elsewhere (see Table 1).

Our study has demonstrated that an autopsy is often not performed after the sudden death of a previously fit adult of less than 50 years of age. Lack of finance and lack of interest (from police, legal authorities and doctors), or a combination of these issues were some of the most important reasons for this. In our survey $30 \%$ of respondents always followed autopsy guidelines and a further $20 \%$ in half of cases. Low resources and insufficient knowledge or expertise were the most common causes of non-compliance. These reasons are not unique to autopsy practice. For example, in a large recent European analysis of challenges in implementing guidelines to prevent spread of multidrug resistant gram negative infections [18] the number of infection control staff, lack of dedicated educational programmes and the number of clinical staff were identified as important reasons for non-compliance.

On a more positive note histology and toxicology were performed in the majority of autopsies, genetic analysis of retained tissue was widely available and the retention of the heart was usually possible. There was also ready access to the opinion of specialists in cardiovascular pathology. However, post-mortem tissues were not always retained frozen for future genetic studies, and this is a matter of particular concern. We also suggest that pathologists should be in more frequent contact with the relatives and family doctors of the deceased to explain the results of the autopsy examination and the need for referral to a specialist cardiologist.

\section{Forensic autopsies}

Our results indicated that European forensic pathologists perform large numbers of autopsies on patients who die of natural causes, emphasizing the increasing role they are now playing in autopsy pathology in Europe. Their practice may have indications extending beyond the identification of the cause of death and may require imaging techniques and more advanced sampling for toxicology, biochemistry and microbiology. Cardiovascular disease can have an important role in many accidental deaths including road traffic collisions [19], trauma [20] or in drowning or water immersion [21].As in clinical autopsies in forensic cases where the cause of cardiac arrest is uncertain a full histological examination with toxicology and retention of tissues for future genetic studies is warranted $[11,22,23]$. 


\section{Autopsies in children}

An Australian study of subjects 1-35 years of age confirmed that SCD occurs in very young subjects [9]. Of the 490 cases, 50 were aged between 1 and 5 years. Paediatric pathologists are likely to perform these autopsies and when non-cardiac causes have been excluded should follow AECVP guidelines for dissection of the heart. Retention of tissue for genetic studies is especially important in children as they are more likely to have potentially inherited cardiomyopathies or structurally normal hearts that may have underlying genetic abnormalities [9, 22]. Cases of the Sudden Infant Death Syndrome (SIDS) are usually dissected by specialist pathologists, following protocols that aim to identify risk factors for asphyxia and potential infective agents [24, 25]. In a recent multi-centre study of 419 cases of SIDS $12.6 \%$ had a "potentially informative" variant in a targeted analysis of 90 genetic heart disease susceptibility genes [26]. However only 4.3\% had an "immediately actionable" abnormality.

\section{Limitations, key concerns and recommendations}

We were disappointed that only $48 \%$ of questionnaires were returned and accept that this is a potential limitation of our study. Furthermore three or more responses were received from Russia, Italy, the Netherlands and the UK. The majority of respondents were forensic pathologists, probably a reflection of the role they play in the delivery of autopsy services. In addition, we suspect that those who did complete the questionnaire may have had a particular interest in autopsy pathology and cardiac disease.

Despite these reservations, it is of particular concern that our study demonstrated important deficiencies in current autopsy practice. These included a low autopsy rate in some centres, a lack of training and expertise in cardiovascular pathology and a lack of knowledge, or failure of application, of anatomical and molecular guidelines for sudden cardiac death autopsies. A larger number of responses from pathologists working in district hospitals would have been desirable, but we doubt that this information would have demonstrated an improvement in overall practice.

Our association recommends that a full autopsy should be performed in any subject less than 35 years who dies suddenly and unexpectedly. Where there is any suspicion of cardiac disease, an anatomical and molecular autopsy should be performed [11, 22, 23]. We believe that it is desirable that this policy is extended to subjects less than 50 years of age. Age limits are necessarily arbitrary, but it is the common experience of specialists in cardiovascular pathology that some cases of sudden cardiac death due to inherited cardiac disease present in patients between 35 and 50 years [27, 28]. In contrast only occasional cases of sudden cardiac death due to inherited causes present in those $>50$ years [27]. A recommendation that all sudden unexpected deaths should have autopsies is unrealistic. However, if there is a family history of inherited cardiac disease and/or premature sudden death, an autopsy should be considered in patients of any age.

Acknowledgements This study was designed and developed by the Association for European Cardiovascular Pathology largely during the Presidencies of Professors Mary N Sheppard and Joaquin S Lucena. Many members of the association, and especially of the board, contributed to the design of the questionnaire which was administered and analysed by ZT in the Department of Community Medicine of the University of Bristol. The results were discussed in detail at board meetings and general assemblies of the association. JB and PJG drafted the manuscript, and $\mathrm{CB}, \mathrm{IK}$ and $\mathrm{KM}$ made substantial contributions to its development. We thank many other members of the association for their contribution to this project.

Authors' contributions JB contributed to the design of the questionnaire, the discussion of the results and the writing of the first draft of the manuscript.

$\mathrm{CB}$ contributed to the design of the questionnaire, the discussion of the results and revisions of the manuscript.

ZT designed the on line version of the questionnaire and was responsible for its circulation and analysis.

IK contributed to the design of the questionnaire, the discussion of the results and revisions of the manuscript.

$\mathrm{KM}$ contributed to the design of the questionnaire, the discussion of the results and revisions of the manuscript.

PJG contributed to the design of the questionnaire, administration of its circulation, led the discussions of the results and with JB wrote the first draft of the manuscript.

Funding No specific funding was obtained. The questionnaire was administered from, and analysed in, the Department of Community Medicine of the University of Bristol.

Compliance with ethical standards This project was designed, developed and approved by the Board of the Association for European Cardiovascular Pathology. No individual patient information was obtained. Ethical approval was not therefore considered necessary.

Conflict of interest The authors declare no conflict of interest.

Open Access This article is licensed under a Creative Commons Attribution 4.0 International License, which permits use, sharing, adaptation, distribution and reproduction in any medium or format, as long as you give appropriate credit to the original author(s) and the source, provide a link to the Creative Commons licence, and indicate if changes were made. The images or other third party material in this article are included in the article's Creative Commons licence, unless indicated otherwise in a credit line to the material. If material is not included in the article's Creative Commons licence and your intended use is not permitted by statutory regulation or exceeds the permitted use, you will need to obtain permission directly from the copyright holder. To view a copy of this licence, visit http://creativecommons.org/licenses/by/4.0/.

\section{References}

1. Goldstein S (1982) The necessity of a uniform definition of sudden cardiac death: witnessed death within 1 hour of the onset of acute symptoms. Am Heart J 103:156-193 
2. Priori SG, Blomström-Lundqvist C, Mazzanti A, Blom N, Borggrefe M, Camm J, Elliott PM, Fitzsimons D, Hatala R, Hindricks G, Kirchhof P, Kjeldsen K, Kuck KH, HernandezMadrid A, Nikolaou N, Norekvål TM, Spaulding C, van Veldhuisen D, ESC Scientific Document Group (2015) 2015 ESC guidelines for the management of patients with ventricular arrhythmias and the prevention of sudden cardiac death: the task force for the Management of Patients with Ventricular Arrhythmias and the prevention of sudden cardiac death of the European Society of Cardiology (ESC). Endorsed by: the Association for European Paediatric and Congenital Cardiology (AEPC). Eur Heart J 36: 2793-2867

3. Deo R, Albert CM (2012) Epidemiology and genetics of sudden cardiac death. Circulation 125:620-637

4. Kong MH, Fonarow GC, Peterson ED (2011) Systematic review of the incidence of sudden cardiac death in the United States. J Am Coll Cardiol 57:794-801

5. Klein L, Hsia H (2014) Sudden cardiac death in heart failure. Cardiol Clin 32:135-144

6. Myerburg RJ, Junttila MJ (2012) Sudden cardiac death caused by coronary heart disease. Circulation 125:1043-1052

7. Hookana E, Junttila MJ, Puurunen VP, Tikkanen JT, Kaikkonen KS, Kortelainen ML, Myerburg RJ, Huikuri HV (2011) Causes of non ischaemic sudden cardiac death in the current era. Heart Rhythm 8:1570-1575

8. Thiene G, Carturan E, Corrado D, Basso C (2010) Prevention of sudden cardiac death in the young and in athletes. Cardiovasc Pathol 19:207-217

9. Bagnall RD, Weintraub RG, Ingles J, Duflou J, Yeates L, Lam L, Davis AM, Thompson T, Connell V, Wallace J, Naylor C, Crawford J, Love DR, Hallam L, White J, Lawrence C, Lynch M, Morgan N, James P, du Sart D, Puranik R, Langlois N, Vohra J, Winship I, Atherton J, McGaughran J, Skinner JR, Semsarian C (2016) A prospective study of sudden cardiac death among children and young adults. N Engl J Med 374:2441-2452

10. Basso C, Burke M, Fornes P et al (2008) Guidelines for the autopsyinvestigation of sudden cardiac death. Virchows Arch 452:11-18

11. Basso C, Aguilera B, Banner J et al (2017) Guidelines for the autopsy investigation of sudden cardiac death. 2017 update from the Association for European Cardiovascular Pathology. Virchows Arch 471:691-705

12. Burton JL, Underwood J (2007) Clinical, educational and epidemiological value of autopsy. Lancet 369:1471-1480

13. Roulson J, Benbow EW, Hasleton PS (2005) Discrepancies between clinical and autopsy diagnosis and the value of post mortem histology; a meta-analysis and review. Histopathology 47:551-559

14. Turnbull A, Osborn M, Nicholas N (2015) Hospital autopsy: endangered or extinct? J Clin Pathol 68:601-604
15. Van den Twell JG, Wittekind C (2016) The medical autopsy as quality assurance tool in clinical medicine: dreams and reality. Virchows Arch 468:75-81

16. Kuijpers GC, Fronczek J, van de Goot FR et al (2014) The value of autopsies in the era of high tech medicine: discrepant findings persist. J Clin Pathol 67:512-519

17. Michaud K, Mangin P, Elger BS (2011) Genetic analysis of sudden cardiac death victims: a survey of current forensic autopsy practices. Int J Legal Med 125:359-366

18. Tacconelli E, Buhl M, Humphreys H, Malek V, Presterl E, Rodriguez-Baño J, Vos MC, Zingg W, Mutters NT, EUCIC StopNegative group (2019) Analysis of the challenges in implementing guidelines to prevent the spread of multidrugresistant gram- negatives in Europe. BMJ Open 9:e027683. https://doi.org/10.1136/bmjopen-2018-027683

19. Dow J, Gaudet M, Turniel E (2013) Crash rates of Quebec drivers with medical conditions. Ann Adv Automot Med 57:57-66

20. Maron BJ, Estes NA (2010) Commotio cordis. N Engl J Med 362: 917-927

21. Tester DJ, Medeiros A, Will ML, Ackerman MJ (2011) Unexplained drownings and the cardiac channelopathies: a molecular autopsy series. Mayo Clin Proc 86:941-947

22. Basso C, Carturan E, Pilichou K, Rizzo S, Corrado D, Thiene G (2010) Sudden cardiac death with a normal heart: molecular autopsy. Cardiovasc Pathol 19:321-325

23. Fellmann F, van El CG, Charron P et al (2019) European recommendations integrating genetic testing into multidisciplinary management of sudden cardiac death. Eur J Hum Genet 27:1763-1773

24. Kinney HC, Thach BT (2009) The sudden infant death syndrome. N Engl J Med 361:795-805

25. Byard RW (2018) The autopsy and pathology of sudden infant death syndrome. In: Duncan JR, Byard RW (eds) SIDS sudden infant and early childhood death: the past, the present and the future. University of Adelaide Press, Adelaide Chapter 24

26. Tester DJ, Wong LCH, Chanana P et al (2018) Cardiac genetic predisposition in sudden infant death syndrome. J Am Coll Cardiol 71:1217-1227

27. Behr ER, Casey AM, Sheppard MN, Wright M, Bowker TJ, Davies MJ, McKenna WJ, Wood DA (2007) Sudden arrhythmic death syndrome: a national survey of sudden unexplained cardiac death. Heart 93:601-605

28. Risgaard B, Winkel BG, Jabbari R, Behr ER, Ingemann-Hansen O, Thomsen JL, Ottesen GL, Gislason GH, Bundgaard H, Haunsø S, Holst AG, Tfelt-Hansen J (2014) Burden of sudden cardiac death in persons aged 1-49 years. A nationwide study in Denmark. Circ Arrhythm Electrophysiol 7:205-211

Publisher's note Springer Nature remains neutral with regard to jurisdictional claims in published maps and institutional affiliations. 